\title{
Patrones idiosincráticos de diversidad genética de peces nativos del Río San Pedro (Cuenca del Río Valdivia), un sistema de la región glaciada del sur de Chile
}

\author{
Idiosyncratic patterns of genetic diversity of native fishes from Río San Pedro (Valdivia \\ River Basin, Región de los Ríos, Chile): a system from glaciated region in southern \\ Chile
}

\author{
Pedro F. Victoriano ${ }^{1,2}$, Iván Vera ${ }^{1}$, Viviana Olmos ${ }^{1}$, Mariem Dib ${ }^{1}$, Bárbara Insunza ${ }^{3}$, Carlos Muñoz- \\ Ramírez ${ }^{1}$, Rolando Montoya ${ }^{3}$, Alfonso Jara ${ }^{4}$ \& Evelyn Habit ${ }^{2,4}$ \\ 1Departamento de Zoología. Facultad de Ciencias Naturales y Oceanográficas. Universidad de Concepción. Casilla 160-C. \\ Concepción. Chile \\ ${ }^{2}$ CIEP. Centro de Investigaciones en Ecosistemas Patagónicos. Coyhaique. \\ ${ }^{3}$ Departamento de Biología Celular. Facultad de Ciencias Biológicas. Universidad de Concepción. Chile. \\ ${ }^{4}$ Unidad de Sistemas Acuáticos. Centro de Ciencias Ambientales Eula. Universidad de Concepción. Chile. \\ E-mail: pvictori@udec.cl
}

\begin{abstract}
RESUMEN
Estudiamos los niveles y patrones de variabilidad genética de ocho especies de peces nativos de la cuenca del río San Pedro (cuenca del río Valdivia, Región de los Ríos, Chile), con el objetivo de evaluar diferencias microevolutivas en especies sometidas a similares condiciones ecológicas e históricas. Las especies consideradas fueron: Diplomystes camposensis, Percilia gillissi, Galaxias platei, G. maculatus, Basilichthys australis, Percichthys trucha, Aplochiton taeniatus y A. zebra. Para ello comparamos indicadores de diversidad genética tanto intra como inter-zonas, e indicadores de estructuración, basados en secuencias de la región de control, para diferentes tramos a lo largo del desarrollo del río. También recuperamos relaciones de parentesco entre haplotipos y su distribución espacial, para cada especie, a partir de redes construidas por parsimonia estadística. Además estimamos indicadores de comportamiento demográfico en el pasado (D de Tajima, Fs de Fu y distribución de frecuencias de diferencias pareadas). Los resultados sugieren que, tanto los patrones de diversidad genética en el río, como las respuestas demográficas, son especie específicos. Las especies más variables, conjuntamente con un alto grado de estructuración y bajo flujo génico en el río son G. maculatus y A. taeniatus. P. trucha mostró altos niveles de estructuración pero valores menores de variabilidad que el par de especies anterior. Las especies menos variables y menos subdivididas en la cuenca son Diplomystes camposensis y P. gillissi. Las demás especies mostraron niveles de variabilidad y estructuración intermedios entre los patrones extremos señalados para las especies anteriores. Las diferencias entre especies se atribuyen a atributos biológicos idiosincráticos tales como nivel de especialización en el uso de hábitat acuático, abundancias poblacionales históricas y comportamientos migratorios. En el caso de Galaxias maculatus, los altos niveles de variabilidad son atribuidos a la mantención histórica de altos tamaños poblacionales, gracias a la posibilidad de usar tanto hábitats marinos como dulceacuícolas. Mientras que los bajos niveles de diversidad e indicadores de variación histórica de tamaños efectivos poblacionales, sugieren que Diplomystes camposensis y Percilia gillissi fueron especies más sensibles y sometidas a reducciones poblacionales en el pasado. Se discuten los resultados en torno a factores ecológicos, biológicos e históricos.
\end{abstract}

Palabras clave: peces nativos, variabilidad genética, conservación genética, Chile, glaciaciones.

\begin{abstract}
We studied the levels and patterns of genetic variability in eight species of native fishes from the Valdivia River Basin (Región de los Rios, Chile), with the aim to estimate microevolutionary differences in species with similar ecological and historical conditions. The species considered were Diplomystes camposensis, Percilia gillissi, Galaxias platei, G. maculatus, Basilichthys australis, Percichthys trucha, Aplochiton zebra and A. taeniatus. We compared genetic diversity indexes both intra and inter-zones, and genetic structure, based on sequences of the control region for different sections along the river. In addition, we recovered relationships among haplotypes and their spatial distribution for each species,
\end{abstract}


based on statistical parsimony networks. Estimators of past demographic behavior (D Tajima, Fs-Fu and mismatch analysis were also obtained. The results suggest that both patterns of genetic diversity in the river such as demographic responses are species specific. The most variable and strongest structured species in the river were G. maculatus and A. taniatus. $P$. trucha showed high structure values but its genetic variation was lower than the first two species. The less variable and less subdivided species were D. camposensis and P. gillissi. The remaining species showed levels of variability and structure intermediate between the two extreme patterns mentioned above. The differences among species are attributed to idiosyncratic biological attributes such as level of specificity in the use of aquatic habitat, population abundances, and historical migration patterns. In the case of $G$. maculatus, high levels of variability are attributed to the historical maintenance of high and stable effective population sizes, due to the ability to use both marine and freshwater habitats. Low levels of genetic diversity and indicators of historical reduction in effective population size, suggests that D. camposensis and P.gillissi were more sensitive and more exposed to population reduction. Results are discussed regarding ecological, biological, and historical factors.

KEYWORDS: native fishes, genetic variation, genetic conservation, Chile, glaciations.

\section{INTRODUCCIÓN}

El estudio de la variabilidad genética en poblaciones naturales es una herramienta fundamental en la determinación de unidades evolutivas naturales (Amos \& Balmford 2001). La valoración de los niveles de diversidad genética de cada especie es a su vez la estimación de la existencia de un recurso a conservar, el cual es uno de los componentes de la biodiversidad (nivel genético) (Lowe et al. 2004). En el contexto de la planificación de proyectos que consideren medidas de conservación a priori, el análisis genético de las poblaciones permite, entre otras cosas, determinar cuántas unidades de reproducción existen en un espacio geográfico determinado, y por ende inferir potenciales efectos de interrupción artificial de unidades naturales. En el caso de los sistemas fluviales, las poblaciones pueden considerarse como complejas unidades que se movilizan a lo largo de un espacio, movilidad que tiene relevancia evolutiva y de gran importancia en la viabilidad de las poblaciones naturales. La fragmentación artificial de tales conjuntos puede implicar la reducción del intercambio de individuos entre poblaciones locales (reducción de flujos génicos), con la consecuente alteración de los regímenes que permiten la mantención de la variabilidad genética, y por ende afectando la adecuación biológica de los individuos y el potencial evolutivo de las poblaciones (Vrijenhoek 1998; Freeland 2006). El caso más extremo es la interrupción total del flujo y por ende del intercambio de individuos a lo largo del río, lo que correspondería a la generación artificial de fragmentos poblacionales vicariantes que se ven reducidos en su capacidad de recuperar variabilidad. Debido a esto, las poblaciones naturales estarían sometidas en ese escenario, a una drástica reducción de su potencial evolutivo y biológico, el cual requiere de la recolonización a partir de otros fragmentos dentro del río. Desde este punto de vista, la dinámica de las poblaciones naturales en su gran mayoría, corresponde a un sistema de tipo metapoblacional, donde la mantención de los procesos demográficos depende de la interconexión entre unidades que funcionan como grupos fuente, y otros que lo hacen como unidades sumidero (Hanski 1994).

Los estudios de secuencias de ADN permiten inferir el nivel de variabilidad genética en un contexto espacial, el grado de flujo génico entre diferentes poblaciones locales, y los grados de parentesco entre grupos de organismos (Avise 2000, 2004; Hartl \& Clark 1997). El desarrollo y perfeccionamiento de estos métodos moleculares desde los años 80 , acompañado de un desarrollo notable de las herramientas matemáticas de análisis, ha permitido progresivamente inferir con cierto grado de precisión tanto el comportamiento demográfico de las poblaciones, como su historia microevolutiva. A esto último se asocia la determinación de los patrones y niveles de variabilidad genética, que, como ya se dijo, resultan importantes en medidas de conservación. La obtención de secuencias de determinadas regiones del genoma permite cuantificar el potencial de recuperación de las poblaciones frente a eventuales eventos de reducción local de variabilidad genética. En este contexto, poblaciones menos fragmentadas y con alta variabilidad genética a lo largo de un sistema fluvial, serán potencialmente mas resilientes a la reducción de la variabilidad frente a una determinada perturbación ambiental (Moran 2002). Lo contrario ocurre en poblaciones altamente fragmentadas y de baja variabilidad genética local. Frente a una situación natural de alta conectividad poblacional, como es el caso de una única población sin estructuración a lo largo de un sistema fluvial, una eventual interrupción del río genera una mayor alteración de tal régimen natural, en comparación al cambio generado sobre un grupo naturalmente fragmentado. Por esta razón, la vagilidad de los peces en un sistema fluvial, junto a los niveles naturales de variabilidad genética, son factores fundamentales de conocer para inferir los potenciales efectos de alguna acción que interrumpa el espacio a lo largo de un río. Por otra parte, especies altamente fragmentadas y con bajo flujo génico entre sí, corren el riesgo de reducir en el tiempo su variabilidad genética, por efectos de deriva. En algunos casos, especies especialistas de peces pueden 
estar asociados a microhábitats fragmentados, tales como pozones, pero esto no quiere decir que tales especies estén genéticamente fragmentadas.

Aunque la riqueza de la ictiofauna dulceacuícola en Chile es baja en comparación a otras partes del mundo, la singularidad evolutiva y ecológica de sus especies, sumada a un alto porcentaje de endemismo, le otorgan gran valor de conservación. La mayor concentración de especies se presenta en la zona central de Chile, lo cual le ha conferido la calidad de punto caliente y área prioritaria para conservación de biodiversidad en el planeta. Tal concentración de biodiversidad en el centro de Chile se explica, por una parte, por la mantención histórica de sistemas ecológicos antiguos que preceden al levantamiento andino, y por otra, a una mayor estabilidad y bondad climática. Esta situación decae hacia el sur de Chile, donde, en general, la biota se empobrece y constituye comunidades más simples (Markgraf 1989). Sin embargo, la menor riqueza específica no implica un menor valor de su ictiofauna, dado que los procesos históricos a los que han estado sometidos los ecosistemas australes chilenos, dentro de los cuales se encuentra la cuenca del río San Pedro, han implicado procesos únicos en el planeta (e.g. ciclos glaciares).

Los ríos chilenos, especialmente al sur de los $38^{\circ} \mathrm{S}$, han estado sometidos a grandes cambios cíclicos ocurridos en el pasado, en los cuales los regímenes climáticos se han alternado de periodos fríos (glaciaciones), y templados (interglaciares) (Moreno et al. 2001; Hulton et al. 2002; Glasser et al. 2004). Entre los efectos más frecuentes de las glaciaciones esta la reducción del rango de distribución espacial de las poblaciones, con la consecuente reducción del tamaño efectivo poblacional, y una reducción asociada de la variabilidad genética. Cuando tales sistemas han estado sometidos a la presencia de grandes masas de hielo, algunas especies han sido excluidas por completo de áreas que quedaron cubiertas por el hielo, como es el caso de las cuencas hidrográficas al sur de los $42^{\circ} \mathrm{S}$ en la vertiente occidental de Los Andes, remitiendo a las poblaciones de peces a refugios distribuidos en áreas aisladas y marginales a los hielos. De este modo, dependiendo de los atributos biológicos de las especies de peces, algunas con altos niveles de tolerancia a la salinidad y anádromas, pudieron refugiarse en ambientes salobres y marinos (e.g. Galaxias maculatus), mientras otras debieron refugiarse en fragmentos no glaciados o en áreas periglaciares (e.g. G. platei; Ruzzante et al. 2008).

La determinación de la distribución espacial y la cuantificación de haplotipos a lo largo del área de estudio permiten, entre otros aspectos, la estimación indirecta de los niveles de flujo génico para cada especie, lo cual, como ya se indicó, es un factor relevante de considerar en medidas de conservación de poblaciones y especies. De hecho, uno de los aspectos más importantes de este estudio es la estimación del grado de movilidad de los peces dentro del sistema fluvial $y$, por ende, estimar el nivel de intercambio de peces entre poblaciones locales a lo largo del río. Con las estimaciones de variabilidad se trató de inferir el estado de las poblaciones en cuanto a su potencial evolutivo. Adicionalmente se indagó acerca de las relaciones de parentesco entre los grupos poblacionales locales, lo cual es un aspecto relevante al momento de hacer aproximaciones para delimitar unidades evolutivamente significativas (ESUs) (Crandall et al. 2000). Por lo tanto, en este trabajo se analizan diversos aspectos de variabilidad genética, tanto intra, como interpoblacional, obtenidos para ocho especies de peces nativos presentes en el río San Pedro, y evaluan los niveles de variabilidad genética y de diferenciación espacial. Esta información a su vez se discute en términos de los eventuales efectos que pudiese tener la alteración de la estructura natural del cauce del río San Pedro, sobre la dinámica de las poblaciones de peces nativos allí existentes. Considerando la variada gama taxonómica, y por ende biológica, de los peces estudiados, a pesar de que éstos cohabitan el mismo sistema fluvial, éstos debieran mostrar diversos patrones de variabilidad dentro del río, dependiendo de la especie que se trate.

\section{MATERIALES Y MÉTODOS}

En este estudio se analizaron las especies Percichthys trucha (Valenciennes, 1833), Percilia gillissi Girard, 1854, Galaxias maculatus (Jenyns, 1842), G. platei Steindachner 1898, Diplomystes camposensis Arratia 1987, Basilichthys australis Eigenmann, 1927, Aplochiton zebra Jenyns, 1842 y A. taeniatus Jenyns, 1842. El análisis espacial de la información se basó en la delimitación de seis zonas, cuatro zonas a lo largo del río San Pedro (Zonas 1 a la 4), las cuales se dispusieron de manera aproximadamente equidistante a lo largo de la cuenca del río San Pedro, desde su origen hasta la confluencia con los sistemas fluviales del complejo río Cruces-Valdivia (Fig. 1). Estas zonas corresponden a: Z1, Sector Nancul; Z2, Sector Pucono; Z3, Sector Purey, y Z4, Sector Huellelhue y aguas abajo (Fig. 1). Dos zonas adicionales (AA1 y AA2), se agregaron en la parte alta del sistema fluvial río Valdivia. No todas las especies estuvieron en ambas zonas de la parte alta del sistema fluvial. Estas zonas corresponden aAA1: Lago Riñihue y AA2: subcuencas de los lagos Neltume, Calafquén y Panguipulli. El detalle de la distribución de las muestras analizadas por especie y por zona se muestra en la Tabla 1. Adicionalmente, y con el objetivo de establecer comparaciones entre las poblaciones del río San Pedro y algunas cuencas independientes, se incluyeron muestras de tres sistemas vecinos. A decir, de los ríos Bueno (CC1, A. zebra y G. platei), Toltén (CC2, A. zebra), y Biobío (CC3, B. australis). Todos los ejemplares fueron fijados en alcohol absoluto (96\%) en terreno, y 
debidamente etiquetados detallando la especie, fecha, localidad, zona y coordenadas geográficas. Posteriormente estos fueron llevados al laboratorio y mantenidos a $-20^{\circ} \mathrm{C}$ hasta su uso en los análisis de ADN.

El ADN total fue extraído del tejido muscular preservado en alcohol al 96\%, siguiendo el protocolo de Fetzner (1999), y usando una batería de extracción QIAGEN DNeasy Tissue. Posteriormente se verificó la calidad y cantidad de cada extracción mediante observación de bandeos en geles de agarosa al 1\%, luego de sembrar $3 \mathrm{uL}$ por individuo. Se amplificó parte de la región de control, considerando que ésta presenta niveles adecuados de variación intraespecífica en escalas geográficas reducidas en vertebrados (Hartl \& Clark 1997). Los cebadores utilizados (primers) y sus respectivas secuencias son detallados en la Tabla 2. Dos de ellos (L19 y 12SARH), fueron adecuados para las especies B. australis, D. camposensis, G. maculatus, G. platei, A. taeniatus y A. zebra. Otros dos (L19 y MT18489H), fueron adecuados para amplificar esta región en $P$. trucha y $P$. irwini. El programa de amplificación óptimo para las seis especies correspondió a: 1 ciclo: $5 \mathrm{~min} / 95^{\circ} \mathrm{C}--0.5 \mathrm{~min} / 60$ ${ }^{\circ} \mathrm{C}$-- $2 \mathrm{~min} / 72^{\circ} \mathrm{C}$; 40 ciclos: $0.5 \mathrm{~min} / 95^{\circ} \mathrm{C}--45 \mathrm{seg} / 54^{\circ} \mathrm{C}$
-- $2 \mathrm{~min} / 72^{\circ} \mathrm{C}$; 1 ciclo: $5 \mathrm{~min} / 72{ }^{\circ} \mathrm{C}$. Los PCR fueron realizados preparando una mezcla que contenía $2,0 \mathrm{uL}$ de templado de ADN, 8 uL de dNTPs, 4ul de buffer 10X, 2 uL de cada partidor, $4 \mathrm{uL}$ de $\mathrm{MgCl}, 24 \mathrm{uL}$ de agua destilada y 0,25 uL de Taq polimerasa. Los productos de PCR fueron evaluados en calidad y cantidad mediante visualización en geles de agarosa al $2 \%$ con bromuro de etidio y detectados con un transiluminador de luz UV. Los productos de PCR fueron posteriormente filtrados en placas Millipore mediante vacío a -20 pulgadas de Hg. El PCR limpio y retenido en las placas fueron resuspendidos en $30 \mathrm{ul}$ de agua y conservados a $-20^{\circ} \mathrm{C}$ hasta su uso en las reacciones de secuenciación. Las PCR limpias fueron posteriormente reamplificadas mediante la llamada reacción de secuenciación, usando BigDye (bases nucleotídicas marcadas), proceso necesario para su posterior ingreso al secuenciador. Los productos de la reacción de secuenciación fueron limpiados mediante el uso de microcolumnas de Sephadex, y su producto fue ingresado al Centro de Secuenciación de la Brigham Young University, Utah, Estados Unidos. A las secuencias obtenidas por el grupo de trabajo, se agregaron secuencias desde Genbank, las que complementaron a las previamente existentes.

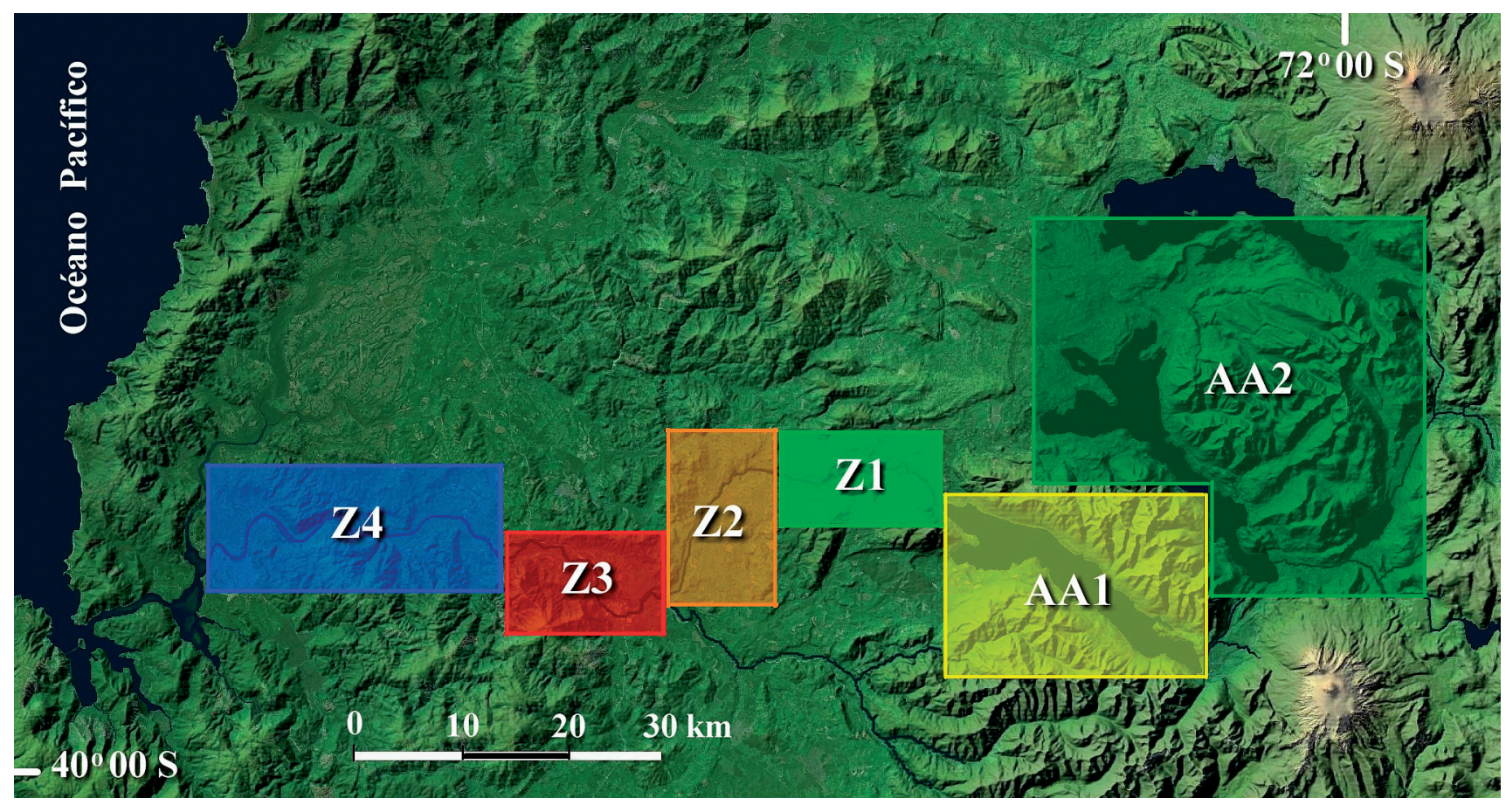

Figura 1. Distribución de las zonas de estudio para el análisis de variabilidad genética de las especies de peces del río San Pedro.

FIGURE 1. Distribution of studied zones for the genetic variation analysis of fishes from Río San Pedro. 
Las secuencias fueron editadas mediante el uso del programa Codon Code Aligner. Posteriormente cada secuencia fue exportada en formato Fasta para su alineamiento en el programa Clustal X. Una vez alineadas, estas secuencias fueron transformadas a archivos en formato "nexus" para su análisis posterior. Para cada especie se estimó la diversidad genética, tanto para todo el río, como para cada zona de muestreo (Fig. 1). La diversidad genética fue estimada a partir de la riqueza de haplotipos, la diversidad haplotípica (Hd) y la diversidad nucleotídica $(\pi)$. Con el fin de evaluar un probable efecto del número de individuos analizados sobre los valores de variabilidad obtenidos, realizamos un análisis de correlación no paramétrica de Spearmann entre el $\mathrm{N}$ y los indicadores respectivos. Adicionalmente se realizaron análisis de frecuencia de comparaciones pareadas (mismatch), con el fin de realizar inferencias demográficas del pasado en cada especie. Tales análisis se complementaron con estimaciones de los índices D’ de Tajima, y Fs de Fu. También se estimó el grado de estructuración mediante el cálculo del índice Fst, y se estimó el flujo génico $(\mathrm{Nm})$ para cada especie, el cual se expresó como el número promedio de individuos intercambiados por generación entre las zonas de muestreo. Estos análisis se realizaron mediante el uso de los programas Mega 3.1 y DnaSP.

Las matrices de secuencias de cada especie fueron analizadas posteriormente en el programa TCS (Clement et al 2000), con el fin de obtener las redes de haplotipos.

TABla 1. Zonas de muestreo y cuencas. Los números indican la cantidad de individuos considerados en el análisis. AT: Aplochyton taeniatus, AZ: Aplochiton zebra, PG: Percilia gillisi, PT: Percichthys trucha BA: Basilichthys australis, GP: Galaxias platei, GM: Galaxias maculatus, DC: Diplomystes camposensis.

TABle 1. Number of samples by zones and basins. AT: Aplochyton taeniatus, AZ: Aplochiton zebra, PG: Percilia gillisi, PT: Percichthys trucha BA: Basilichthys australis, GP: Galaxias platei, GM: Galaxias maculatus, DC: Diplomystes camposensis.

\begin{tabular}{|c|c|c|c|c|c|c|c|c|c|}
\hline Zonas & CUENCA & AT & $\mathrm{AZ}$ & PG & PT & $\mathrm{BA}$ & GP & GM & $\mathrm{DC}$ \\
\hline AA2 & Valdivia & 5 & 2 & & & 4 & 15 & & 13 \\
\hline AA1 & Valdivia & 10 & & & & & 2 & & \\
\hline $\mathrm{Z1}$ & Valdivia & & & 4 & 5 & 15 & 5 & 6 & 14 \\
\hline $\mathrm{Z} 2$ & Valdivia & & & 6 & 7 & 19 & 9 & 4 & 9 \\
\hline $\mathrm{Z3}$ & Valdivia & & & 5 & 6 & 9 & 1 & 5 & 5 \\
\hline Z4 & Valdivia & 4 & & 5 & & 21 & 2 & 6 & 8 \\
\hline $\mathrm{CC} 1$ & Bueno & & 6 & & & & 8 & & \\
\hline $\mathrm{CC} 2$ & Toltén & & 3 & & & & & & \\
\hline $\mathrm{CC} 3$ & Biobío & & & & & 1 & & & \\
\hline $\mathrm{N}$ Total & & 19 & 11 & 20 & 18 & 69 & 42 & 21 & 49 \\
\hline
\end{tabular}

\section{RESULTADOS}

Se obtuvo secuencias para un total de 249 ejemplares repartidos en diferente número en las ocho especies. El detalle de individuos de cada especie por zona de muestreo se presenta en la Tabla 1. Para las especies G. maculatus, G. platei, O. mauleanum, B. australis, A. taeniatus, A. zebra y D. camposensis, se pudo secuenciar fragmentos mitocondriales de una longitud superior a los 1000 pares de bases. Para las especies $P$. gillissi y $P$. trucha en cambio, se obtuvo secuencias de longitud aproximada a los 400 pares de bases.

Las especies representadas por un mayor número de individuos en el estudio fueron $B$. australis, con 69 individuos, G. platei, con 42 y D. camposensis, con 49 individuos. El menor número de individuos para los que se obtuvo secuencias de buena calidad fue para la especie $A$. 
zebra, con 11 ejemplares. De acuerdo al número de zonas de las que se obtuvo muestras con resultados, las especies que están representadas en mas áreas son G. platei (7 zonas), $D$. camposensis (6) y B. australis (6). Cuatro de las especies estuvieron representadas por muestras provenientes de cuencas vecinas (A. zebra, B. australis, D. camposensis y G. platei). Los indicadores de variabilidad se muestran en la Tabla 5. En las correlaciones no paramétricas, ni la diversidad haplotípica $(\mathrm{Rs}=0,047 ; \mathrm{p}=0,910)$, ni la nucleotídica $(\mathrm{Rs}=0,000 ; \quad \mathrm{p}=1,000)$, resultaron significativamente asociadas con los tamaños muestrales. Esto significa que los niveles de variabilidad genética para las especies analizadas no dependieron de la cantidad de peces secuenciados. Estas correlaciones también se aplicaron a cada especie individual para lo cual tampoco hubo significancia estadística.

La Fig. 2A muestra la red de haplotipos para A. taeniatus, para la cual se detectaron 19 tipos de secuencias distintas, cada una de las cuales se presentó en un solo individuo. Es decir, no se detectaron secuencias redundantes en esta especie. La mayor cantidad de secuencias se detectó en la zona AA1, correspondiente al primer tramo aguas arriba del Lago Riñihue (10 secuencias), mientras la zona AA2 mostró sólo cinco tipos de secuencias distintas. Cuatro secuencias provenientes de la parte baja de la cuenca (Zona 4), quedaron desligadas de la red anterior, debido al alto número de sustituciones (mutaciones) respecto al grupo de las zonas AA1 y AA2. Los haplotipos de AA1 se relacionan irregularmente en la figura, con los del área AA2, lo que indica que entre ambas zonas existen relaciones entre diferentes haplotipos. En general, el arreglo de los haplotipos en la red indica que entre las zonas AA1 y AA2 existen individuos emparentados, aunque estas relaciones son más estrechas al interior de la zona AA2. Los individuos provenientes de la zona 4 constituyen un linaje claramente distinto de haplotipos y espacialmente bien delimitado. Ningún haplotipo de la zona 4 fue compartido con alguna de las otras dos zonas. De acuerdo a los niveles de variabilidad genética, esta especie muestra valores altos de diversidad haplotípica y riqueza haplotípica, mientras que su diversidad nucleotídica fue intermedia respecto a las demás especies (Tabla 5). La diversidad haplotípica al interior de cada tramo estudiado fue alta, debido a una distribución de frecuencia equitativa entre éstas. Sin embargo, la diversidad nucleotídica dentro de cada área fue baja indicando un número reducido de sustituciones entre áreas. De acuerdo a los niveles de estructuración genética, éstos sugieren que $A$. taeniatus es una especie con altos niveles de estructuración (Tabla 3). Esto fue consistente con un valor bajo de flujo génico $(\mathrm{Nm})$, cuyo valor es de 0,05 , el más bajo de todas las especies analizadas. Este valor se debió fundamentalmente a la diferenciación de las partes extremas de la cuenca
(AA1+AA2 v/s Z4). De acuerdo al gráfico del análisis de mismatch, éste mostró dos tramos de máxima frecuencia (distribución bimodal). Uno en torno a valores bajos de diferencias, principalmente entre cero y 15 sustituciones, y otro entre aproximadamente 45 y 64 sustituciones. Esto sugiere que al interior de esta especie existen al menos dos linajes evolutivos, o grupos de haplotipos con cantidades de diferencias contrastantes (Fig. 3A-B). Al analizar de la misma manera, por separado a los individuos de la zona 4, este gráfico sugiere un mayor número de sustituciones que entre los individuos de las zonas AA1 y AA2, sin embargo, estas diferencias son menores a las mostradas por el análisis total. Esto indica que la ocurrencia de la distribución bimodal del análisis total corresponde a las comparaciones entre ejemplares de la parte (AA1 + AA2), y los de la parte baja (Z4).

La especie A. zebra estuvo representada por un total de 11 haplotipos diferentes, de los cuales solo dos provienen de la cuenca del río Valdivia (Fig. 2B). Esto no permitió realizar un análisis acabado para el área focal (sistemas asociados al río San Pedro), debido al bajo número de individuos y proveniencia de un sólo tramo (AA1). Los demás individuos provienen de las cuencas de los ríos Bueno y Toltén. Los haplotipos provenientes de la zona AA1 se relacionaron más cercanamente con los individuos de la cuenca CC2 (Toltén). Se detectó un número considerable de sustituciones entre las dos secuencias de la parte alta del Riñihue. Las demás secuencias se disponen de manera no consistente con la pertenencia a distintas cuencas, lo que indica que existen individuos emparentados alternadamente en ambas cuencas vecinas (ríos Bueno y Toltén). Esto indica que los individuos de $A$. zebra intercambian individuos entre sistemas fluviales. No hubo haplotipos presentes en más de un individuo, y la diversidad haplotípica fue máxima en todas las áreas analizadas (Tabla 3). La diversidad nucleotídica fue moderada en relación a lo detectado en las demás especies $(\pi=0,037)$. El valor de D' de Tajima sugiere que ésta es una especie en expansión poblacional. Los valores de flujo génico para todo el conjunto fue alto $(\mathrm{Nm}=13,99)$, $\mathrm{y}$ el indicador de estructuración Fst fue bajo $(\mathrm{Fst}=-0,02)$. Esto resulta relevante si se tiene en cuenta un intercambio considerable de individuos entre cuencas vecinas. Esto es en parte corroborado por los arreglos de relaciones de parentesco entre haplotipos (Fig. 2B). De las cuencas vecinas sólo dos individuos fueron notoriamente más divergentes, las cuales corresponden a las secuencias TraAZ01 (de Toltén), y RHUE02 (del Bueno). La gráfica del mismatch mostró tres categorías de diferencias con una mayor frecuencia, lo cual indica que existirían al menos tres grupos o linajes. Sin embargo, como ya se detalló anteriormente, este resultado incluye individuos de más de una cuenca. 


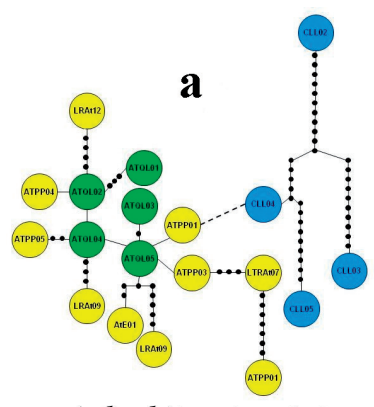

Aplochiton taeniatus

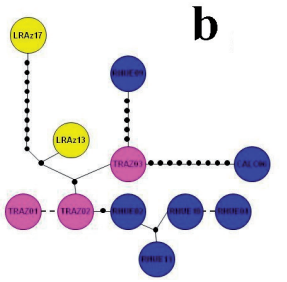

Aplochiton zebra

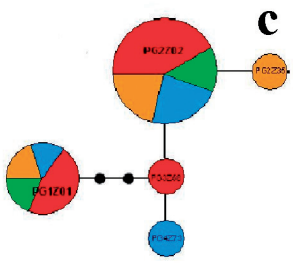

Percilia gillissi

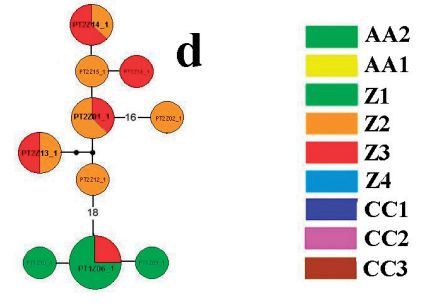

Percichthys trucha

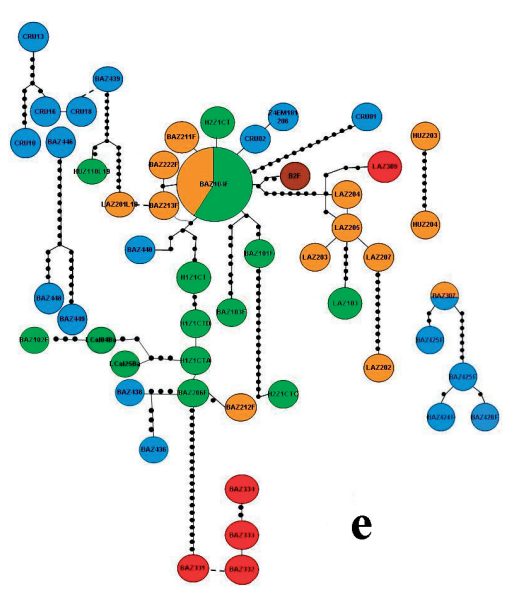

"Basilichthys australis '

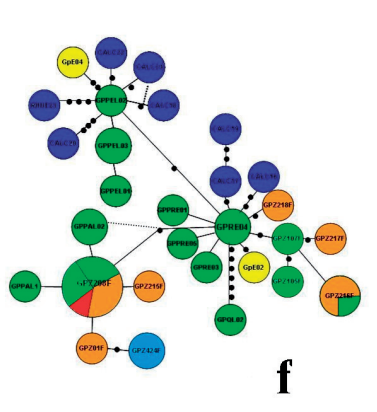

Galaxias platei

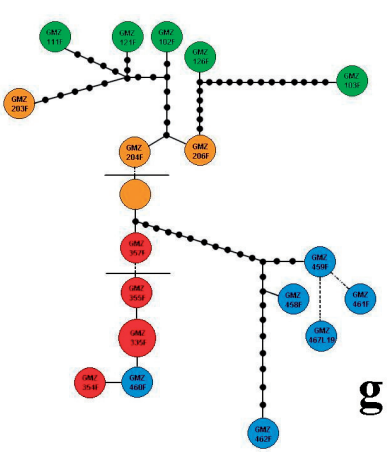

Galaxias maculatus

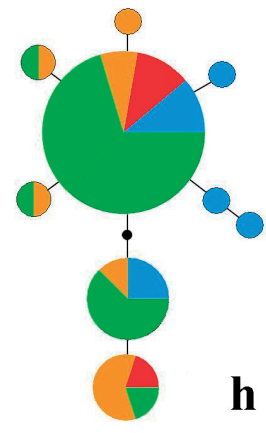

Diplomystes camposensis

FIGURA 2. Redes de haplotipos para las ocho especies de peces nativas del río San Pedro, basados en secuencias de la región de control (ADN mitocondrial).

FIGURE 2. Haplotype networks for each studied species from Río San Pedro, based on sequences of control region.

TABLA 2. Secuencias de los partidores usados para amplificar la región de control de las especies focales. L19 (L): 5' - CCA CTA GCT CCC AAA GCT A - 3'; 12SAR (H): 5' - ATA GTG GGG TAT CTA ATC CCA GTT - 3'; L19*: 5' - ACC ACT AGC ACC CAA AGC TA - 3'; MT16489H: 5' - CCT GAA GTA GGA ACC AGA TG - 3'.

TABLE 2. Primer pairs used to amplify the Control Región. L19 (L): 5' - CCA CTA GCT CCC AAA GCT A - 3'; 12SAR (H): 5' - ATA GTG GGG TAT CTA ATC CCA GTT - 3'; L19: 5' - ACC ACT AGC ACC CAA AGC TA - 3'; MT16489H: 5' - CCT GAA GTA GGA ACC AGA TG - 3'.

\begin{tabular}{ll}
\hline Especie & Partidores \\
\hline Basilichthys australis & L19 (L), 12SAR (H) \\
Diplomystes camposensis & L19 (L), 12SAR (H) \\
Galaxias maculatus & L19 (L), 12SAR (H) \\
Galaxias platei & L19 (L), 12SAR (H) \\
Aplochiton taeniatus & L19 (L), 12SAR (H) \\
Aplochiton zebra & L19 (L), 12SAR (H) \\
Percichthys trucha & L19, MT16489H \\
Percilia gillissi & L19, MT16489H \\
\hline
\end{tabular}


Tabla 3. Indicadores de variabilidad genética y estructuración para las especies de peces analizadas. N: número de Individuos, Nhap: número de haplotipos, $\boldsymbol{\pi}$ : Diversidad nucleotídica, Fs: test Fs de Fu de selectividad neutral, D: D de Tajima, Nm: flujo génico, Fst: índice de estructuración. * : valores significativos. Códigos de especies como en la Tabla 1.

Table 3. Genetic variation and structure for the fish species analyzed. N: number of individuals, Nhap: number of haplotypes, $\pi$ : nucleotide diversity, Fs: Fu test, D: Tajima's test, Nm, gene flow, Fst: structure index. *: Significant values. Species codes as in Table 1.

\begin{tabular}{|c|c|c|c|c|c|c|c|c|c|}
\hline Especie & Zona & $\mathrm{N}$ & Nhap & $\mathrm{Hd}$ & $\pi$ & Fs & $\mathrm{D}$ & $\mathrm{Nm}$ & Fst \\
\hline \multirow[t]{4}{*}{ AT } & $\mathrm{AA} 2$ & 5 & & 1 & 0,00349 & & & & \\
\hline & AA1 & 10 & & 1 & 0,01008 & & & & \\
\hline & $\mathrm{Z4}$ & 4 & & 1 & 0,01308 & & & & \\
\hline & Total & 19 & 19 & 0.99400 & 0,0326 & $-3,940 *$ & $-0,27648$ n.s & 0,05 & 0,84 \\
\hline \multirow[t]{4}{*}{$\mathrm{AZ}$} & AA1 & 2 & & 1 & 0,01133 & & & & \\
\hline & $\mathrm{CC} 1$ & 6 & & 1 & 0,08373 & & & & \\
\hline & $\mathrm{CC} 2$ & 3 & & 1 & 0,02392 & & & & \\
\hline & Total & 11 & 11 & 1 & 0,03696 & $-0,930$ n.s. & $-1,81840 *$ & 13,99 & $-0,02$ \\
\hline \multirow[t]{5}{*}{ PG } & $\mathrm{Z1}$ & 4 & & 0,70000 & 0,00400 & & & & \\
\hline & $\mathrm{Z} 2$ & 6 & & 0,70000 & 0,00540 & & & & \\
\hline & $\mathrm{Z3}$ & 5 & & 0,80000 & 0,00590 & & & & \\
\hline & $\mathrm{Z4}$ & 5 & & 0,60000 & 0,00550 & & & & \\
\hline & Total & 20 & 5 & 0,60000 & 0,00500 & 0,494 n.s. & $0,32400 \mathrm{~ns}$ & 2,03 & 0,14 \\
\hline \multirow[t]{5}{*}{ PT } & $\mathrm{Z1}$ & 5 & & 0,70000 & 0,00200 & & & & \\
\hline & $\mathrm{Z} 2$ & 7 & & 0,95200 & 0,02080 & & & & \\
\hline & $\mathrm{Z3}$ & 6 & & 0,93300 & 0,02380 & & & & \\
\hline & $\mathrm{Z4}$ & 0 & & $\mathrm{n} / \mathrm{c}$ & $\mathrm{n} / \mathrm{c}$ & & & & \\
\hline & Total & 18 & 10 & 0,91500 & 0,03590 & 1,544 n.s. & $0,43988 \mathrm{~ns}$ & 0,40 & 0,62 \\
\hline \multirow[t]{7}{*}{$\mathrm{BA}$} & $\mathrm{AA} 2$ & 4 & & 0,70000 & 0,00010 & & & & \\
\hline & $\mathrm{Z1}$ & 15 & & 0,91500 & 0,02400 & & & & \\
\hline & $\mathrm{Z} 2$ & 19 & & 0,90500 & 0,00452 & & & & \\
\hline & $\mathrm{Z3}$ & 9 & & 0,81400 & 0,04419 & & & & \\
\hline & $\mathrm{Z4}$ & 21 & & 0,97810 & 0,08247 & & & & \\
\hline & $\mathrm{CC} 3$ & 1 & & - & - & & & & \\
\hline & Total & 69 & 51 & 0,95740 & 0,04254 & 1,290 n.s. & $-1,31013$ n.s & 0,71 & 0,26 \\
\hline \multirow[t]{8}{*}{ GP } & AA2 & 15 & & 0,91429 & 0,02391 & & & & \\
\hline & AA1 & 2 & & 1 & 0,01082 & & & & \\
\hline & $\mathrm{Z1}$ & 5 & & 0,6 & 0,0013 & & & & \\
\hline & $\mathrm{Z} 2$ & 9 & & 0,75 & 0,00665 & & & & \\
\hline & $\mathrm{Z3}$ & 1 & & $\mathrm{n} / \mathrm{c}$ & $\mathrm{n} / \mathrm{c}$ & & & & \\
\hline & $\mathrm{Z4}$ & 2 & & 0 & 0 & & & & \\
\hline & $\mathrm{CC} 1$ & 8 & & 1 & 0,02061 & & & & \\
\hline & Total & 42 & 29 & 0,91363 & 0,01716 & $-5,746^{* *}$ & $-2,05561 *$ & 0,94 & 0,21 \\
\hline \multirow[t]{5}{*}{ GM } & $\mathrm{Z1}$ & 6 & & 1 & 0.013 & & & & \\
\hline & $\mathrm{Z} 2$ & 4 & & 1 & 0,02300 & & & & \\
\hline & $\mathrm{Z3}$ & 5 & & 0,90000 & 0,00100 & & & & \\
\hline & $\mathrm{Z} 4$ & 6 & & 1 & 0,05900 & & & & \\
\hline & Total & 21 & 19 & 0,99500 & 0,06200 & $-3,573^{*}$ & $0,8589 \mathrm{~ns}$ & 0,27 & 0,48 \\
\hline
\end{tabular}


Continuación TABLA 3

\begin{tabular}{llcccccccc}
\hline Especie & Zona & N & Nhap & Hd & $\pi$ & Fs & D & Nm & Fst \\
\hline DC & AA2 & 13 & & 0,36919 & 0,00036 & & & & \\
& Z1 & 14 & & 0,57958 & 0,00052 & & & & \\
& Z2 & 9 & & 0,79585 & 0,00100 & & & & \\
& Z3 & 5 & & 0,70000 & 0,00079 & & & & \\
& Z4 & 8 & & 0,85714 & 0,00080 & & & & \\
& Total & 49 & 9 & 0,62111 & 0,00064 & $-8,782^{* *}$ & $-2,08094 *$ & 4,10 & 0,10 \\
\hline
\end{tabular}

P. gillissi es una especie de niveles bajos de variabilidad genética en la cuenca del río San Pedro. Esto fue denotado tanto por el número reducido de haplotipos ( 5 en toda el área de estudio), como por el bajo número de diferencias entre haplotipos. La Fig. $2 \mathrm{C}$ muestra las asociaciones entre los tipos de secuencias detectadas para esta especie. En ella se puede ver que dos de los haplotipos son abundantes y presentes a lo largo de toda el área de estudio. Las demás secuencias fueron detectadas en un único individuo cada una y se distribuyen en zonas diferentes (zonas 2, 3 y 4). Los valores de diversidad nucleotídica $(\pi)$, fueron bajos en toda el área de estudio, con un valor total de $\pi=0,005$. Por su parte, la diversidad haplotípica (Hd) fue moderada, con un valor de 0,600. Lo anterior fue acompañado por un valor bajo del índice de fijación (Fst $=0,140)$, y un alto grado de flujo génico $(\mathrm{Nm}=2,03)$. Este último índice fue uno de los tres mayores de todas las especies estudiadas en el río San Pedro. Los valores de diversidad genética fueron regulares y bajos a lo largo de toda el área de estudio. El análisis de mismatch entregó una curva multimodal con máximas frecuencias en valores relativamente bajos pero con tres niveles de diferencias entre secuencias (Fig. 3-D). Esto indica que, aunque es baja la variabilidad genética al interior del área de estudio, en ella existen linajes de haplotipos distintos, pero distribuidos en forma homogénea a lo largo del río.

P. trucha mostró un alto nivel de diversidad filogenética en la cuenca del río San Pedro. En ésta se detectó un total de 10 haplotipos para las tres zonas en que se obtuvo muestras de la especie (Fig. 2D). Este arreglo fue consistente en términos generales con la proveniencia de los individuos aunque se evidencia un importante intercambio entre las zonas 2 y 3 . De esta forma, en la red se observa un grupo de secuencias mayoritariamente de las zonas 3 y 4 , secuencias que difieren en un número alto de sustituciones respecto a la parte alta de la cuenca del San Pedro (Z1). En general, en la parte baja de su distribución en la cuenca, esta especie muestra mayor diversidad evolutiva que la parte superior del río. Los niveles de diversidad genética detectados en $P$. trucha fueron altos aunque más bajos que las de otras especies, con un valor total de Hd de 0,915 y un $\pi$ de 0,0359 . Al comparar las tres zonas donde se detectó esta especie, tanto la diversidad nucleotídica como haplotípica fueron mayores en las zonas 2 y 3 (Tabla 3). Consistentemente con la distribución de haplotipos observados en el arreglo de la red, el valor de Fst fue alto $(F s t=0,620)$, indicando un alto grado de estructuración genética, y un valor bajo de flujo génico $(\mathrm{Nm}=0,40) . \mathrm{El}$ análisis de mismatch entregó un gráfico con tres máximos de frecuencias (Fig. 3E), uno de valores bajos de diferencias, correspondiente a comparaciones predominantemente al interior de la zona 1, otro de nivel intermedio que se generó fundamentalmente al comparar secuencias al interior de las zonas 2 y 3 , y otro conjunto de comparaciones con un alto número de diferencias se obtuvo al comparar secuencias entre los grupos de las zonas $1 \mathrm{v} / \mathrm{s}$ $(2+3)$. En términos generales, los resultados obtenidos para esta especie indican altos niveles de variabilidad genética y alto grado de estructuración en la cuenca.

La Fig. 2E muestra la red de haplotipos para B. australis. En total se observaron 51 tipos de secuencias, las cuales en su mayoría no se detectaron en más de un individuo. Esta es la especie de mayor riqueza haplotípica de las analizadas, y la asociación de sus haplotipos en la red mostró valores muy dispares del número de sustituciones. Solo tres haplotipos se detectaron en más de un individuo. El individuo considerado en este análisis, proveniente de la cuenca del Biobío, se asoció al grupo de las zonas 1 y 2 . Gran parte de los haplotipos provenientes de la zona baja del Valdivia (Z4), no fueron conectados con la red principal, debido al alto número de sustituciones. Un importante nivel de divergencia se observó también en cuatro haplotipos de la zona 3. Estos aparecen conectados a la red principal y asociados a individuos de la zona 1. Por el contrario, un predominio de un número bajo de cambios se detectó en los tramos Z1 y Z2, cuyos haplotipos aparecen asociados con un número menor de sustituciones. Los valores de diversidad haplotípica y nucleotídica tienden a ser mayores en la parte baja de la cuenca (Tabla 3). El grado de estructuración poblacional sugerido por el Fst fue moderado, al igual que el nivel de intercambio o flujo génico en el área total de estudio $(\mathrm{Nm}=0,71)$. De acuerdo a los resultados del análisis de comparaciones pareadas entre haplotipos, se obtuvieron configuraciones diferentes dependiendo 
del clado analizado (Fig. 3F-H). El criterio para definir los grupos de comparaciones de mismatch se basó en las asociaciones filogenéticas. De este modo, aquel haplogrupo que se asocia al haplotipo de B. australis del Biobío (B2F), fue considerado como un grupo distinto. El resto de los haplotipos predominantemente de la zona 4 , fue definido como otro grupo por su gran divergencia observada en la red de haplotipos de la Fig. 2E. Considerando estos subconjuntos de individuos, el grupo de haplotipos de la parte baja y que incluye al del Biobío, muestra una distribución multimodal, tanto con una frecuencia importante de comparaciones de bajo número de diferencias, como con un alto número de ellas. Esto sugiere que B. australis en la parte baja de la cuenca está representado por haplotipos de alta diversidad y de una historia evolutiva compleja. El análisis para el total de los individuos de $B$. australis entrega una gráfica de distribución con proporción mayor de comparaciones de bajo número de diferencias. Esto indica que al incluir las poblaciones interiores, se agregan casos de haplotipos con un bajo número de sustituciones, y por ende grupos de peces con una historia evolutiva más nueva. Por último, las comparaciones para el otro subconjunto divergente muestran una gráfica multimodal, con un alto número de casos de gran número de diferencias, sugiriendo un conjunto de haplotipos provenientes de diferentes linajes.

G. platei mostró valores considerables de variabilidad genética. Sin embargo, en este contexto debe ser considerada la inclusión de un número importante de ejemplares de la cuenca vecina del río Bueno. En el arreglo de los haplotipos en la red (Fig. 2F), se pudo observar un predominio de casos no redundantes, en cambio, son pocos los haplotipos que se observaron en más de un individuo, y en más de una zona. Sólo dos casos se distribuyen en más de un tramo del río, una secuencia detectada en AA2, Z1, Z2 y Z3, con una amplia distribución. Otra secuencia se detectó en las zonas AA2 y Z2. Los individuos analizados de la zona baja (Z4), se asociaron al grupo de haplotipos de amplia distribución. Los haplotipos de la cuenca del río Bueno se asociaron predominantemente con las detectadas en la parte alta de la cuenca (AA2), y con las zonas Z1 y Z2. Los dos haplotipos provenientes de la zona AA1 se dispusieron en grupos diferentes de haplotipos, pero ambos asociados a secuencias provenientes de la zona contigua AA2. En general el arreglo de haplotipos indica un grado intermedio de estructuración poblacional, y un concordante nivel de flujo génico $(\mathrm{Nm}=$ $0,94)$. La diversidad haplotípica fue dispar pero con valores relativamente altos, y los valores de diversidad nucleotídica fueron moderados a bajos. El resultado del análisis de mismatch (Fig. 3-I), muestra una distribución multimodal, pero con valores predominantes en categorías bajas de diferencias entre secuencias. Esto indica que, aunque hay haplogrupos distantes, hay haplotipos con un moderado número de cambios mutacionales entre secuencias. De acuerdo a la distribución de mismatch observada, esta especie estaría en una fase intermedia entre expansión y fase estable.

G. maculatus es una de las especies que mostró mayores niveles de variabilidad genética y de estructuración en este estudio. En el río San Pedro se detectó para esta especie la presencia de 19 haplotipos, los que a su vez se asociaron entre sí con un alto número de sustituciones (Fig. 2G). Esto generó valores altos tanto de diversidad nucleotídica como haplotípica, y a lo largo de todo el río (Tabla 3). El promedio de $\pi$ fue de 0,062 , mientras que el de Hd fue de 0,995. Al comparar las cuatro zonas del área de estudio, el valor más alto de diversidad nucleotídica se detectó en la zona 4, es decir en la parte baja del río. La diversidad haplotípica fue regular a lo largo de todo el río, lo cual indica que el número de haplotipos y su representación numérica fue similar en toda el área de estudio. Una característica importante detectada en G. maculatus del río Valdivia fue el alto grado de estructuración espacial en la distribución de haplotipos $(\mathrm{Fst}=0,48)$, lo cual resulta consistente con un valor bajo de flujo génico $(\mathrm{Nm}=0,27)$ (Tabla 3). El patrón espacial describió dos grupos de haplotipos, uno fundamentalmente distribuido en la parte superior del río (zona 1, y pocas secuencias en la zona 2), y otro remitido a la parte baja de la cuenca (principalmente en las zonas 3 y 4). El análisis de mismatch entregó una distribución claramente multimodal, con valores altos de frecuencia para valores altos de diferencias pareadas (Fig. 3J).

La Fig. 2H muestra la red de haplotipos para ejemplares de la especie D. camposensis. En ésta se puede distinguir un total de nueve haplotipos, los cuales en general muestran un bajo número de sustituciones. Un haplotipo se encontró ampliamente distribuido a lo largo del río y en alta frecuencia, estando presente en las zonas AA2, Z1, Z2, Z3 y Z4. Otros dos haplotipos se distribuyen en más de un tramo del río. Uno presente en las zonas AA2, Z1, Z2 y Z4, y otro distribuido en las zonas 1, 2 y 3. Estos dos últimos están estrechamente emparentados con el primero destacado como de amplia distribución. La mayor riqueza haplotípica se observó en los tramos Z2 y Z4 de la cuenca del Valdivia. En cuanto a los niveles de diversidad genética, esta especie mostró niveles moderados de diversidad haplotípica, en relación a las otras especies analizadas. Los niveles de flujo génico fueron relativamente altos $(\mathrm{Nm}=$ 4,10 ), indicando un nivel importante de intercambio de individuos en el sistema fluvial. Concordantemente, el nivel de estructuración poblacional fue moderado. En síntesis, la especie $D$. camposensis es una especie con moderada riqueza de haplotipos, baja diversidad nucleotídica y considerables niveles de flujo génico. La parte alta de la cuenca (AA2), compartió haplotipos con todas las demás zonas de la cuenca del Valdivia, lo cual sugiere un alto intercambio entre ambos 
tramos de este sistema fluvial. De acuerdo al valor obtenido para el índice D` de Tajima, y Fs de Fu (Tabla 3), esta especie estaría en una fase de expansión poblacional. El análisis de frecuencia de diferencias pareadas entre haplotipos (Fig. $3 \mathrm{~K}$ ) sugiere que existe una baja cantidad de sustituciones entre ellos, con una tendencia a la distribución unimodal y alta frecuencia de bajo número de diferencias. La mayor parte de las comparaciones mostraron valores inferiores a cinco sustituciones, lo cual correspondería a un conjunto con una historia microevolutiva relativamente reciente, y en una fase de expansión poblacional.
Cinco de las ocho especies mostraron valores significativos, ya sea para el índice Fs de Fu o para el D de Tajima. $A$. taeniatus, G. platei, G. maculatus y D. camposensis mostraron valores negativos y significativos de Fs, mientras que el $\mathrm{D}$ de Tajima fue negativo y significativo para las especies A. zebra, G. platei y D. camposensis. De acuerdo a estos índices, las especies que estarían en una situación de equilibrio mutación deriva en la cuenca del Valdivia son $P$. trucha, P. gillissi y B. australis.
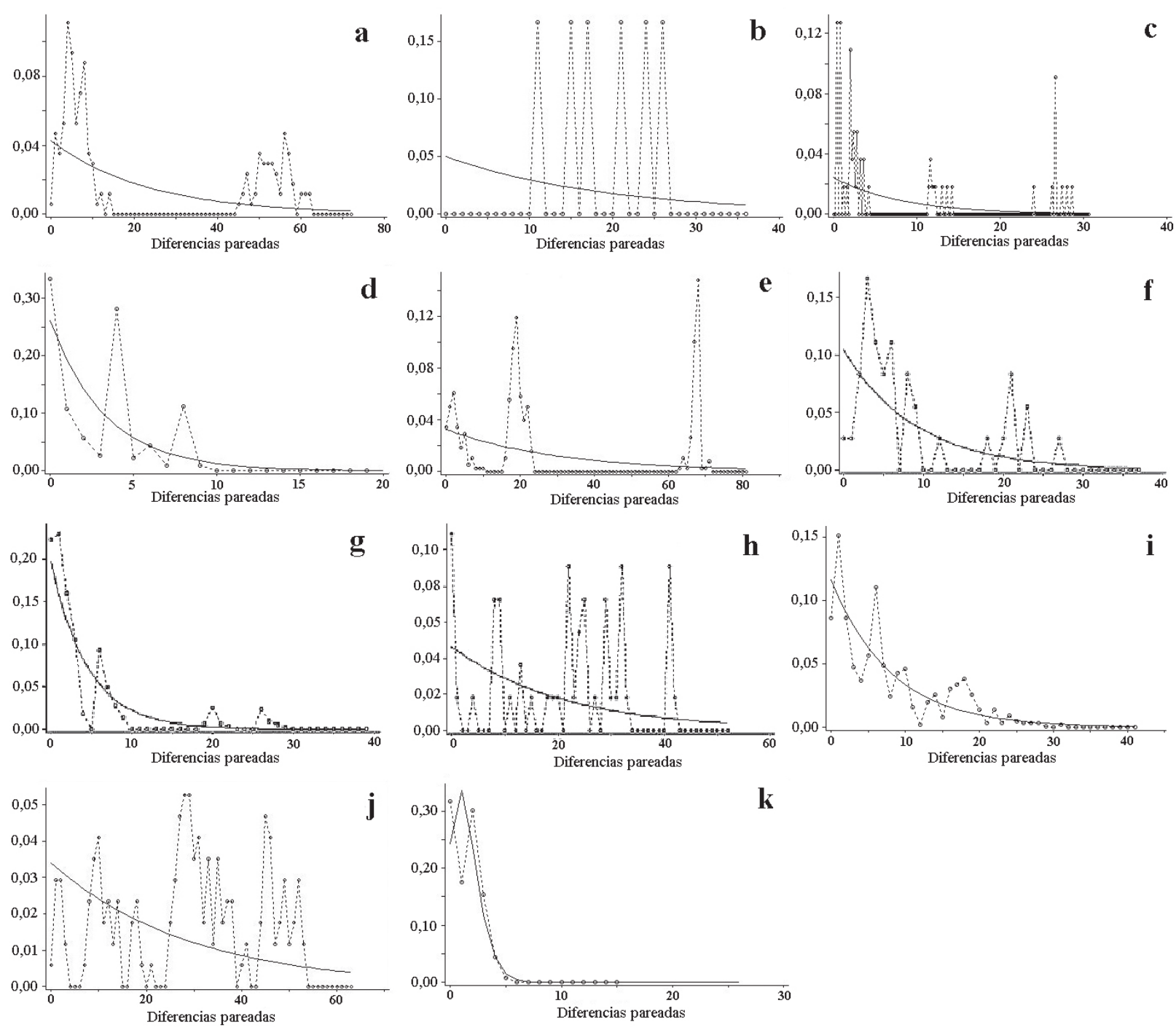

FIgURA 3. Gráficos de distribución de diferencias pareadas ("mismatch"), para las ocho especies de peces estudiadas para el río San Pedro. A-B: A. taeniatus; C: A. zebra; D: P. gillissi; E: P. trucha; F-H: B. australis; I: G. platei; J: G. maculatus; K: D. camposensis.

Figure 3. Mismatch distributions for the eight studied species from Río San Pedro. A-B: A. taeniatus; C: A. zebra; D: P. gillissi; E: P. trucha; F-H: B. australis; I: G. platei; J: G. maculatus; K: D. camposensis. 


\section{DISCUSIÓN}

La conformación de los patrones microevolutivos del sur de Sudamérica, y por ende al interior de las comunidades del sur de Chile, han obedecido tanto a procesos históricos complejos, como a atributos particulares de cada grupo biológico (Sérsic et al. 2011). Los atributos biológicos idiosincráticos, entre los que destacan las capacidades de dispersión, las interacciones biológicas (Peterson 2009), y los atributos de historia de vida constituyen factores importantes en la generación de patrones de variabilidad genética, y por ende de la estructura filogeográfica. De esto depende en gran medida la naturaleza de la dispersión, las condiciones refugiales para cada especie, y por ende los niveles de diversificación y afección por procesos históricos como el clima y los cambios geológicos. Los resultados de este estudio muestran diferentes patrones y niveles de variabilidad genética dependiendo de la especie de pez que se trate. Esta situación con arreglos idiosincráticos a nivel específico de los niveles de variabilidad genética ha sido detectado por otros estudios de comparación de patrones de variabilidad, dejando en claro la relevancia de los atributos biológicos de cada taxón en las respuestas poblacionales y microevolutivas (e.g. Carstens et al. 2005). Esto es esperable si se considera que cada especie consta de una historia de vida particular, lo cual ha sido demostrado tener relación tanto con los niveles de estructuración y de variabilidad intra e interpoblacional (Cook et al. 2006), como con fenómenos azarosos de la generación y mantención de la variabilidad genética (por ejemplo, estocasticidad coalescente; Knowles et al. 2007; Hickerson 2006). Esto constituye un hecho relevante al momento de discutir los probables efectos que pueden generar las modificaciones del sistema fluvial que constituyen fragmentación del hábitat. En este contexto, el razonamiento básico para cualquier caso es que el efecto de barreras artificiales será más drástico sobre especies con tamaños efectivos poblacionales menores y con alta vagilidad a lo largo del río, puesto que dichas modificaciones significarían una mayor alteración respecto a la situación natural (Moore et al. 2007). De esta manera, el efecto de barreras artificiales puede ser variado, dependiendo de la movilidad de las especies, los tamaños efectivos poblacionales $(\mathrm{Ne})$, y de qué tan variable es una especie genéticamente (Moyle et al. 2003). Así por ejemplo, especies con un alto grado de estructuración indican baja movilidad y por ende, la interrupción del flujo génico implicará pocos cambios a la situación natural de una especie. Para el caso de las especies analizadas, dos de ellas constituyen casos de flujo génico elevado a lo largo de toda el área de estudio, como el caso de $P$. gillissi y D. camposensis. Ambas especies se comportan prácticamente como una única población en el río San Pedro (no así aguas arriba del lago Riñihue), por lo que cualquier interrupción de la movilidad natural podría tener efectos sobre la dinámica natural de mantención de la variabilidad genética total, y por ende podría afectar su dinámica evolutiva y eventualmente su capacidad para responder a reducciones poblacionales futuras. Este patrón fue ya sugerido por Ruzzante et al. (2006), para especies de Percilia y Percichthys en otras cuencas del país. Sin embargo, al momento de inferir posibles efectos sobre las poblaciones naturales, debe considerarse otros factores, entre los que cuentan atributos de tipo demográfico. Es decir, los cambios que pueden surgir de las reducciones de flujo génico y de los tamaños efectivos poblacionales, dependerá fuertemente de cuan abundante es la especie en el área en cuestión, y de cuan resiliente es frente a perturbaciones ambientales (Piller et al. 2005). En este caso, si se considera como referente las abundancias detectadas en el río San Pedro a lo largo del estudio, $P$. gillissi aparece como una especie abundante dentro del sistema. En esta especie, la presencia de haplotipos a lo largo de las cuatro zonas, sugiere que, junto con ser poco variable, presenta alta vagilidad a lo largo del sistema fluvial. Aunque con una situación similar de variabilidad y flujo génico que la anterior, la especie $D$. camposensis es una especie notoriamente menos abundante a lo largo del río, lo cual la convierte en una especie claramente más sensible frente a eventuales efectos de barreras artificiales. A juzgar por los análisis de mismatch, y por los indicadores Fs y D de Tajima, $D$. camposensis es una especie que pudo haber pasado históricamente por periodos de reducción drástica de sus poblaciones locales, y estaría experimentado un proceso de expansión poblacional. Un extremo opuesto es el caso de G. maculatus y B. australis, las cuales probablemente se han comportado en la cuenca como una especie de altos tamaños efectivos poblacionales y además éstos habrían sido estables en el tiempo. En el caso de G. maculatus, los resultados sugieren la ocurrencia de dos poblaciones con un alto grado de aislamiento, una asociada biológicamente a aguas dulces y en tramos altos y medios de la cuenca, y otra asociada a aguas de mayor salinidad (ambientes más potamales y estuarinos). La distribución de haplotipos sugiere además que ambos grupos se reproducirían en zonas distintas del río, y que las secuencias de cada grupo son altamente divergentes evolutivamente. Para el caso de G. maculatus, los dos grupos distinguidos sugieren dos conjuntos de poblaciones con alto grado de divergencia evolutiva, en relación a los niveles de divergencia total para la cuenca. Esto indica que dos grupos han permanecido por un tiempo considerable separados o con un flujo génico muy bajo, lo que probablemente se asocie a biologías reproductivas diferentes. Campos (1973) destacó la ocurrencia de poblaciones migratorias diádromas en la parte baja de la cuenca del Río Valdivia, pero hasta ahora no había sido abordado por medio de indicadores moleculares. Más aún, para la parte alta de la cuenca no se había encontrado evidencia de poblaciones no diádromas aisladas reproductivamente de las costeras. En esta especie, la ocurrencia de alto número de diferencias tanto entre secuencias del grupo de la parte baja (zonas 3 y 4), 
como al interior de la parte alta, sugiere que en ellos están representados diversos linajes, probablemente haplotipos de diversas edades evolutivas. Esto es corroborado por el análisis de mismatch, el cual muestra una curva de numerosos picos, a lo largo de una amplia gama de valores de diferencias entre pares de secuencias. Esto indica que las secuencias presentes en el área de estudio muestran tiempos de divergencia tanto bajos como altos al interior de la misma cuenca hidrográfica.

Tres de las especies analizadas mostraron un alto grado de estructuración y con flujos génicos bajos al menos en algunos de los tramos del sistema fluvial. Estas especies son A. taeniatus, G. maculatus y P. trucha. La primera se diferencia marcadamente entre los tramos de lagos de la parte alta de la cuenca respecto a la Zona 4 (potamal). Algo semejante ocurre para $P$. trucha, lo cual indica que existen tramos en la cuenca que actúan como barreas para formar dos subconjuntos poblacionales. La ocurrencia de dos grupos de poblaciones de esta especie claramente disgregados a lo largo del río, puede corresponder a grupos de diferente historia de vida. Para galáxidos, y específicamente para G. maculatus, ha sido reportada la existencia, tanto de grupos anádromos y asociados al mar, como grupos cuyo ciclo de vida completo se realiza en ambientes de agua dulce ("landlocked") (e.g. Zattara \& Premoli 2005; Humphries 2004). A diferencia de las especies anteriores, aunque con una magnitud menor de estructuración, P. trucha se diferencia principalmente en la parte baja de su distribución dentro de la cuenca. Los resultados para esta especie indican que, junto con presentar alta diversidad genética en la cuenca, ésta se comporta como dos poblaciones locales distribuidas en tramos contiguos del río, una en la zona 1 , y otra en las zonas 2 y 3 . El caso de $P$. trucha es distinto, debido fundamentalmente a la ocurrencia de alta estructuración en la parte baja. Tal diferenciación es relevante en el contexto de la conservación genética, pudiendo existir dos linajes evolutivos muy distintos y probablemente originados con un tiempo de divergencia alto, y por ende que debieran tratarse como unidades de conservación distintos al interior de esta especie (Crandall et al. 2000). Procesos microevolutivos complejos han sido denotados por Ruzzante et al. (2011).

En el caso de A. taeniatus, ésta incluyó haplotipos de la parte alta de la cuenca (AA1, AA2), desde el lago Riñihue hacia arriba, más ejemplares de la parte baja (Z4), dejando un vacío de análisis en las zonas intermedias. Sin embargo, el nivel de diferenciación alto de los haplotipos de la parte baja, hacen pensar en dos unidades poblacionales discretas reales, donde la parte aguas arriba del lago Riñihue se comportaría como una única población.

Las variaciones de estructura genética que pueden resultar como consecuencia de la fragmentación del hábitat, ya sea de origen natural o artificial, depende tanto de la abundancia poblacional, como de la capacidad de respuesta de estas poblaciones frente a alteraciones generadas en el medio (Piller et al. 2005). De esta forma, es posible suponer que una especie de baja abundancia en toda su distribución, como es $D$. camposensis, es un candidato a experimentar alteraciones importantes en su estructura genéticopoblacional, considerando el alto grado de conectividad, bajos efectivos poblacionales y un importante grado de especialización en el uso del hábitat. Por su parte, G. platei, con una moderada estructuración, tendría un efecto moderado sobre su estructura genética actual, frente a eventuales cambios del hábitat. En el caso de la especie B. australis, esta muestra en general una alta diversidad de haplotipos en toda la extensión de la cuenca, y una clara diferenciación poblacional. La ocurrencia de linajes de haplotipos tan diferentes en la zona potamal puede corresponder a un caso donde más de un taxón específico cohabita en este tramo. Frente al eventual efecto de alteraciones del curso fluvial, podría generar efectos de magnitud intermedia en esta especie, considerando los grados de estructuración y distribución de haplotipos. En el caso de esta especie, la existencia de poblaciones más variables en los tramos más bajos de la cuenca podría ser explicado por la ocurrencia de ambientes estables y de alto grado de conectividad, los cuales tienden a albergar mayores niveles de diversidad genética. De esta manera, la ocurrencia de mayor variabilidad genética en $B$. australis se puede interpretar como la existencia de grupos de individuos provenientes de poblaciones menos afectadas por eventos de reducción poblacional en el pasado, sobre todo en las partes bajas de la cuenca. Mayores niveles de estabilidad ambiental histórica serían más frecuentes en poblaciones de ambientes marinos o estuarinos (e.g. McLean et al. 1999).

En cuanto a la relación evolutiva de las poblaciones provenientes de cuencas vecinas, la situación varía dependiendo de la especie. En el caso de A. zebra, aunque los haplotipos de las cuencas de los ríos Bueno y Toltén se asociaron predominantemente intracuenca, tres asociaciones son intercuenca. Esto sugiere que los grupos de ríos distintos pertenecen a la misma especie y a su vez muestran cierta cercanía evolutiva. Para el caso de G. platei, es interesante destacar para esta especie la asociación de los haplotipos de la cuenca vecina del río Bueno, con los de la parte alta del Valdivia (AA2). Esto podría estar asociado a eventos de colonización antiguos, o a la retención de haplotipos ancestrales en ambas áreas geográficas. Eventos de intercambio intercuencas han sido reportados para otros peces de Chile y Argentina, a partir de análisis filogeográficos mediante marcadores de ADNm (Ruzzante et al. 2006).

Como se planteó anteriormente, las respuestas microevolutivas que pueden presentar los peces frente a 
la construcción de barreras, es especie especifico, dada la singularidad biológica de cada taxón (Cook et al. 2006). Tales respuestas no pueden ser predichas sólo a partir de atributos biológicos superficiales. Por ejemplo, teóricamente, la tendencia es a inferir mayores grados de vagilidad, y por ende de mayor flujo génico, en especies de mayor tamaño corporal (e.g. Knouft \& Page 2003). Sin embargo, en este caso tal tendencia no se cumple, y tanto peces de talla adulta reducida (e.g. G. maculatus), como de talla mayor (e.g. P. trucha), muestran niveles relativamente altos de estructuración genética. Considerando los niveles de flujo génico a lo largo del sistema fluvial del río Valdivia, un ordenamiento jerárquico de mayor a menor magnitud es como sigue: $D$. camposensis $>P$. gillissi $>G$. platei $>$ B. australis $>$ P. trucha $>$ G. maculatus $>$ A. taeniatus. Este arreglo ordinal debiera ser a su vez consistente con los niveles de susceptibilidad de estas especies frente a la imposición de barreras artificiales en el río San Pedro. Tales interrupciones artificiales del flujo génico podrían generar, no sólo la alteración de los patrones naturales de variabilidad genética, sino también podría generar cambios de índole adaptativo y reducción de la adecuación biológica. Tales efectos han sido evidenciados en peces de otras partes del mundo (Moore et al. 2007), y probablemente ocurriría en mayor o menor magnitud dependiendo de la especie, en los peces del río San Pedro.

\section{AGRADECIMIENTOS}

Este estudio fue financiado por COLBUN S.A. y por el proyecto FONDECYT 1080082. El proyecto DIUC Semilla Patagonia 210.310.057-1SP financió la publicación.

\section{BIBLIOGRAFÍA}

Amos, W. \& Balmford, A. 2001. When does conservation genetics matter? Heredity 87(3): 257-265.

Avise, J. C. 2000. Phylogeography. The History and Formation of Species. Harvard University Press. USA, 447 pp.

Avise, J. C., 2004. Molecular Markers, Natural History, and Evolution. Second Edition. Sinauer, Sunderland, 684 pp.

CAmpos, H. 1973. Migration of Galaxias maculatus (Jenyns) (Galaxiidae, Pisces) in Valdivia Estuary, Chile. Hydrobiologia 43:301-312

Crandall, K., Bininda-Emonds, O., Mace, G. \& Wayne, R.K. 2000. Considering evolutionary processes in conservation biology. Trends in Ecology and Evolution 15(7): 290-295.

Clement, M., Posada, D. \& Crandall, K. 2000. TCS: a computer PROGRAM to ESTIMATE GENE GENEALOGIES. MOleCUlar ECOLOGY 9(10): 1657-1660.

Cook, B. D., Baker, A. M., Page, T. J., Grant, S. C., Fawcett, J. H., Hurwood, D. A \& J. M. Hughes. 2006. Biogeographic history of an Australian freshwater shrimp, Paratya australiensis (Atyidae): the role life history transition in phylogeographic diversification. Molecular Ecology 15: 1083-1093.

FEtzNeR, J. 1999. Extracting high-quality DNA from shed reptiles skins: a simplified method. BioTechniques 26:1052-1054

Freeland, J.R. 2005. Molecular Ecology. John Wiley and Sons, Ltd. The Atrium, Southern Gate, Chichester, West Sussex, EngLAND, 400 pp

Glasser, N. F., Harrison, S., Winchester, V \& Aniya, M. 2004. Late Pleistocene and Holocene palaeoclimate and glacier fluctuations in Patagonia. Global and planetary change 43: 79-101.

HANSKi I., 1994. A practical model of metapopulation dynamics. Journal of Animal Ecology 63:151-162.

Hartl, D.L. \& A.G. Clarck. 1997. Principles of Population Genetics. 3th Edition. Sinauer Assoc. Massachussetts, 542 pp.

Hickerson, M. J., Dolman G. \& Moritz, C. 2006. Comparative phylogeography summary statistics for testing simultaneous vicariance. Molecular Ecology 15:209-223

Hulton, N.R.J., Purvesa, R.S., McCullocha, R.D., Sugdena, D.E. \& Bentley, M.J. 2002. The Last Glacial Maximum andd eglaciation in southern South America. Quaternary Science Reviews 21: 233-241.

Humphries, P. 2004. Morphological variation in diadromous and landlocked populations of the spotted galaxias, Galaxias truttaceus, in Tasmania, south-eastern Australia. Environmental Biology of Fishes 27(2): $97-105$.

Knouft, L. J. \& Page, L. 2003. The evolution of body size in extant groups of North American freshwater fishes: speciation, size distributions, and Cope's rule. The American Naturalist 161(3): 413-421.

Knowles, L.L., Crastens, B.C \& Keat, M.L. 2007. Coupling genetic and ecological-niche models to examine how past population distribution contribute to divergence. Current Biology V17: 940-946.

Lowe, A., Harris, S. \& Ashton, P. 2004. Ecological Genetics: Design, Analysis, and Application. Blackwell Publishing, Maldon, U.K. 344 pp.

Markgraf, V. 1989. Paleoclimates in Central and South America since 18000 B.P. based on pollen and lake-level records. Quaternary Science Review 8:1-24.

Mclean, D., D.E. Hay \& Taylor, E. 1999. Marine population structure in an anadromous fish: life-history influences patterns of mitochondrial DNA variation in the eulachon, Thaleichthys pacificus. Molecular Ecology 8(1): 143-158.

Moore, S., Gow, J.L., Taylor, E.B. \& Hendry, A.P. 2007. Quantifying the constraining influence of gene flow on adaptive divergence in the lake-stream threespine stickleback system. Evolution 61-8: 2015-2026.

Moran, P. 2002. Current conservation genetics: building an ecological approach to the synthesis of molecular and quantitative genetic methods. Ecology of Freshwater Fish 11: 30-55.

Moreno, P. I., Jacobson, G. L., Lowell, T. V. \& Denton, G.H. 2001. Interhemispheric climate links revealed from a Late-glacial cool episode in southern Chile. Nature 409: 804-808

Moyle, L.C., Stinchcombe, J.R., Hudgens, B.R. \& Morris, W.F. 2003. Conservation genetics in the recovery of endangered animal species: a review of US endangered species 
Diversidad genética en peces del río San Pedro: Pedro F. Victoriano ET AL.

recovery plans. Animal Biodiversity and Conservation 26(2): 85-95.

Peterson, A. T. 2009. Phylogeography is not enough: The need for multiple lines of evidence. Frontiers of Biogeography 1: $19-25$

Piller, K.R., C. Wilson, C. Eunmi \& J. Lyons, 2005. Conservation genetics of inland lake trout in the upper Mississippi river basin: stocked or native ancestry? Transactions of the American Fisheries Society 134:789-802

Ruzzante, D., Walde, S.J., Cussac, V., Dalebut, M., Siebert, J., Ortuba, S. \& Habit, E. 2006. Phylogeography of the percichthyidae (pises) in Patagonia: roles of orogeny, glaciation, and volcanism. Molecular Ecology 2949-2968

Ruzzante, D. E., Walde, S. J., Gosse, J. C., Cussac, V. E., Habit, E., ZemlaK, T. S. \& Adams, E.D.M. 2008. Climate control on ancestral population dynamics: insight from patagonian fish phylogeography. Molecular Ecology 17: 2234-2244.
Ruzzante, D. S. J. Walde., P. J. Macchi, M. Alonso \& Barriga, J.P. 2011. Phylogeography and phenotypic diversification in the Patagonian fish Percichthys trucha: the roles of Quaternary glacial cycles and natural selection. Biological Journal of the Linnean Society 103: 514-529.

Sérsic, A. Cosacov, A. Cocucci, L. Johnson, R. Pozner, L. Avila, J. W. Sites \& Morando, M. 2011. Emerging phylogeographical patterns of plants and terrestrial vertebrates from Patagonia. Biological Journal of the Linnean Society 103: 475-494.

VRIJENHOEK, R.C. 1998. Conservation genetics of fhreshwater fish. Journal of Fish Biology 53(A): 394-412.

Zattara, E. \& Premoli, A.C. 2005. Genetic structuring in Andean landlocked populations of Galaxias maculatus: effects of biogeographic history. Journal of Biogeography 32(1): 5 -14 .

Recibido: 02.01.12

Aceptado: 27.02.12 